\title{
Wittgenstein on Freedom of the Will: \\ Not Determinism, Yet Not Indeterminism
}

\section{Thomas Nadelhoffer}

This is a prepublication draft. This version is being revised for resubmission to a journal.

\begin{abstract}
Since the publication of Wittgenstein's Lectures on Freedom of the Will, his remarks about free will and determinism have received very little attention. Insofar as these lectures give us an opportunity to see him at work on a traditional-and seemingly intractable-philosophical problem and given the voluminous secondary literature written about nearly every other facet of Wittgenstein's life and philosophy, this neglect is both surprising and unfortunate. Perhaps these lectures have not attracted much attention because they are available to us only in the form of a single student's notes (Yorick Smythies). Or perhaps it is because, as one Wittgenstein scholar put it, the lectures represent only "cursory reflections" that "are themselves uncompelling." (Glock 1996: 390) Either way, my goal is to show that Wittgenstein's views about freedom of the will merit closer attention.
\end{abstract}

All of these arguments might look as if I wanted to argue for the freedom of the will or against it. But I don't want to.

--Ludwig Wittgenstein, Lectures on Freedom of the Will

Since the publication of Wittgenstein's Lectures on Freedom of the Will, ${ }^{1}$ his remarks from these lectures about free will and determinism have received very little attention. ${ }^{2}$ Insofar as these lectures give us an opportunity to see him at work on a traditional-and seemingly intractablephilosophical problem and given the voluminous secondary literature written about nearly every

\footnotetext{
${ }^{1}$ Wittgenstein's "Lectures on Freedom of the Will" will be abbreviated as LFW 1993 in this paper (see bibliography) since I am using the version reprinted in Philosophical Occasions (1993). For all other references to Wittgenstein, I use the standard citation keys developed by Pichler, Biggs, and Szeltner (2011).

2 To my knowledge, the only discussions of LFW 1993 in the scholarly literature are found in Brenner (2001), Dilman (1999), and Shanker (1993), and in each case, the discussion is fairly cursory.
} 
other facet of Wittgenstein's life and philosophy, this neglect is both surprising and unfortunate. Perhaps these lectures have not attracted much attention because they are available to us only in the form of a single student's notes (Yorick Smythies). Or perhaps it is because, as one leading Wittgenstein scholar put it, the lectures represent only "cursory reflections" that "are themselves uncompelling" (Glock 1996: 390). Either way, my goal is to show that Wittgenstein's views about freedom of the will merit closer attention.

On my reading of the Lectures on Freedom of the Will, Wittgenstein is trying to show that there are two ways of looking at human actions (namely, as either free or unfree). By his lights, these different view-points are better viewed as pre-theoretical attitudes that we bring to bear on the facts than as empirical or metaphysical theories about the facts themselves. Given different psychological dispositions, we are inclined to play certain (sometimes incommensurable) language games with concepts like "free will," "determinism," and the like. Being attentive to the psychological underpinnings of the debate about free will can help us see the debate in the right explanatory light. On Wittgenstein's view, there are no empirical or metaphysical facts which could resolve whether we are really free or unfree. Whether one thinks we are free in a given context will depend on one's temperament and the language games one happens to find intuitive. So, my main order of business in this paper will be to situate Wittgenstein's remarks on freedom of the will within his broader approach to philosophical problems. Having discussed Wittgenstein's two lectures in some detail, I will conclude by saying a few words about how and why these lectures deserve a second look by philosophers interested in the traditional debate about the nature and limits of human agency. 


\section{Wittgenstein's Lectures}

At the beginning of the first lecture we find Wittgenstein examining the hard determinist's claim that if an agent's decisions and actions are wholly determined by natural laws, then these decisions and actions are not free. In addressing this issue, Wittgenstein asks, "could one say that the decision of a person was not free because it was determined by natural laws?-There seemed to be a point in saying that if it is determined by natural laws...then a decision can't be said to be free" (LFW 1993: 429). By his lights, the hard determinist is led to the conclusion that we are not free because he views natural laws as if they are rails that physically compel events and actions to happen necessarily and inevitably (LFW 1993: 429). Wittgenstein suggests that this conclusion is confused and he claims that the analogy between laws and rails that fuels it is misleading. After all, when we normally talk of rails, we realise that they could-and often do-bend, break, or malfunction. Lest we forget these possible malfunctions, we should avoid the temptation to say that the rails determine the objects along them necessarily. On Wittgenstein's view, treating causal laws as if they were "like rails compelling a locomotive" (PI 1958: 220) is both confused and misguided because it involves a failure to recognise the "difference between being causally determined and being logically determined" (PI 1958: 220).

In the Tractatus, Wittgenstein connects this distinction between causality and logical necessity directly to the issue of free will. As he says, "The freedom of the will consists in the fact that future actions cannot be known now. We could only know them if causality were an inner necessity, like that of logical deduction.-The connection of knowledge and what is known is that of logical necessity" (TLP 1955: 5.136). On this view, freedom of the will is better construed as an 
epistemic issue than as a metaphysical one. We are free, when we are free, simply because we don't and can't know everything about the future as a practical matter. So long as the universe seems to us like an indeterminate garden of forking paths, to borrow a popular metaphor from the free will literature, it may make sense to say that actions are free even though they may nevertheless be causally determined. ${ }^{3}$ It is only by mistaking causal determinism for logical necessity that it starts to seem as if we must always do precisely and only what we do and nothing else (even if we can't know advance what it is that we purportedly must do). If we focused instead on the phenomenology of agency - that is, what it feels like to deliberate and make choices in a world that is epistemically open-we may understandably be inclined to talk about freedom of the will.

As the following remarks indicate, the difference between physical and logical determinism is a recurring theme for Wittgenstein:

The machine (its structure) as symbolising its action: the action of a machine- I might say at first-seems to be there in it from the start. What does that mean? If we know the machine, everything else, that is its movement, seems to be already completely determined. "We talk as if these parts could only move in this way, as if they could not do anything else." How is this-do we forget the possibility of their bending, breaking off, melting, and so on? Yes; in many cases we don't think of that at all. We use a machine, or the picture of the machine, to symbolise a particular action of the machine [...] But we do not say this kind of thing when we are concerned with predicting the actual behavior of a machine. Here we do not in general forget the possibility of a distortion of the parts and so on. (RFM 1978: 122; see also PI 1958: 193)

\footnotetext{
${ }^{3}$ This may sound like a kind of proto-compatibilism, but I suggest in $\S 2$ that reading Wittgenstein in this way is a mistake.
} 
In this passage, Wittgenstein is contrasting the logical necessity of kinematics with the causal necessity that "compels" a machine part to move as it does. On his view, the former is much "harder" than the latter insofar as the former involves logical necessity while the latter merely involves physical contingency. That something ensues regularly and predictably-such as the movements of a machine or the behavior of a human agent-in no way entails that it happens necessarily.

Although we could say, for instance, that the train goes from Paris to Berlin because of the rails, we cannot say the train must go as it does because of the rails. To say this would be to once again ignore the aforementioned possibility of malfunction. After all, locomotives often break down and fail to arrive at their "determined" destination owing to mechanical problems. According to Wittgenstein, we are led to ignore this possibility because we are tempted to view the world as if it were governed by a "causal nexus" that is analogous to the "connexion of two machine parts by means of a mechanism, say a train of cog-wheels" (Z 1967: 580; see also PI 1958: 613). This is yet another recurring theme in Wittgenstein's philosophy and a tendency that he diagnoses and criticises as early as 1914 with the following remark, "it is clear that the causal nexus is not a nexus at all" (TB 1979: 84). This claim connects up with what he says later in the

\section{Tractatus:}

In no way can an inference be made from the existence of one state of affairs to the existence of another entirely different from it. There is no causal nexus which justifies such an inference. The events of the future cannot be inferred from those of the present. Superstition is the belief in the causal nexus. (TLP 1955: 5.136-5.1362) 
These last remarks are particularly salient to our present discussion because they are immediately followed by the aforementioned distinction between causal and logical relations. We could only know about future events in advance "if causality were an inner necessity, like that of logical deduction" (TLP 1955: 5.1362). But because Wittgenstein thinks that the only kind of necessity is logical necessity, he thinks that it can never be the case that it is necessary "for one thing to happen because another has happened" (TLP 1955: 6.37). In this respect, we cannot know that a certain set of physical events will invariably happen in advance-which represents a kind of category mistake.

On this view, causal laws only tell us what happens to be the case, not what must necessarily be the case. Here Wittgenstein claims that natural laws are nothing more than contingent explanations of the events and regularities of the world. (LFW 1993: 429) Laws are merely explanatory, they are not metaphysical-that is, they are tools we use to explain the regularities we find in the world. The law of gravitation, for instance, is not a physical force that compels objects to move one way or the other. Rather, it is an explanation of an observed physical regularity - an explanation that could, and in the case of quantum physics, has, turned out to be inadequate for some domains and purposes.

Nevertheless, the hard determinist will still insist that even if we do not know which laws compel objects at the quantum level to move as they do, there must nonetheless, be some as yet unknown natural law or hidden variable which causes and sufficiently explains the motion. And while Wittgenstein allows that we could follow the hard determinist in concluding that some unknown law holds, he cautions us against such an assumption. After all, why say that there must 
always be some law that explains any given series of events, even in cases where we are clearly unable to detect any regularity, rather than allowing that in some cases there is no law at all-or that the law is merely probabilistic? Presumably, these responses are no less reasonable-and no less warranted - than the conclusion that even though we have no idea what makes quantum particles behave as they do, surely something must determine their movement.

Wittgenstein suggests that the same can be said about the hard determinist's assumption that some unknown laws must compel humans to behave as they do, even if we have no idea what those laws might be:

Suppose I said: 'Our decisions are determined by the circumstances of our education and our whole anatomy. We don't know in what way they are determined. We can't predict except in very rare circumstances and then very roughly. All the same it is reasonable to think they follow natural laws and are determined'. 'They follow natural laws' would only mean that one day we may, though it is most misleading and out of the question in fact, forecast man's actions. But thinking this is no reason for our saying that if the decisions follow natural laws - that if we know the laws which they follow-they are therefore in some way compelled. What on earth would it mean that the natural law compels a thing to go as it does? The natural law is correct, and that's all. (LFW 1993: 430)

Here Wittgenstein attempts to diagnose what might lead people to have one response rather than the other. First, he asks why someone would view the world through the lens of determinism, that is, "why should people think of natural laws at all as compelling events?" (LFW 1993: 430). In answering this question, Wittgenstein claims that the concept "law" (a) connects up with civil laws that compel us to behave in certain ways if we are to avoid being punished, and (b) seems to evoke notions of inevitability and necessity, rather than mere regularity and probability (LFW 1993: 430; see also RFM 1978: 116). In this sense, the concept "law" hooks up with the fatalistic notion that what will happen in the future is already laid down somewhere. It 
is as if a book has been written, which contains "an authoritative description of those rails on which all events run" (LFW 1993: 430). On this view, the scientist's job is to discover and translate the book of nature-a task which Wittgenstein admits has yielded amazing results. After all, despite the fact that there is a large realm of nature where we have been entirely unable to discover regularities and formulate natural laws, there are many areas where we have been incredibly successful. This success had misled hard determinists into adopting a fatalistic attitude towards the world and our place in it (LFW 1993: 431).

While Wittgenstein believes that the hard determinist's point of view certainly represents one peculiar but understandable way of looking at the world, there are other frameworks available. After all, as he says:

There is no reason why, even if there were regularity in human decisions, I should not be free. There is nothing about regularity which makes anything free or not free. The notion of compulsion is there if you think of the regularity as compelled; as produced by rails.... When we bring in the notion of compulsion this already shows one peculiar way of looking at events. (LFW 1993: 431)

To illustrate this point, Wittgenstein considers the hard determinist's claim that a thief who steals a banana acts as inevitably as a falling stone. On this view, once a stone is released, the laws of physics compel it to fall exactly as it does. And if we know in advance enough information about the antecedent conditions-e.g., the weight of the stone, the height from which it is being dropped, the speed of the wind, etc. - we would presumably be able to ascertain exactly how fast the stone will fall and precisely where it will land. Thus, by the hard determinist's lights, just as the stone cannot help but fall to the ground given certain antecedent conditions, the thief cannot help but steal the banana. By applying the natural laws of psychology, physiology, and 
sociology to the thief we could, in principle, know in advance that he is going to steal the banana with the same certitude that we know in advance that the rock will fall to the ground. Consequently, the hard determinist is tempted to treat the thief and the stone in much the same way as we treat the path of a bullet in ballistics - namely, by saying, "this bullet inevitably goes that way, as inevitably as if it moves on rails" (LFW 1993: 431). But what does it mean to say that the bullet goes inevitably? After all, to say that it is inevitable that the bullet goes a particular way is to once again ignore a number of variables that could prevent the bullet from going where we predicted-e.g., the gun misfiring, a bird flying into the path of the bullet, etc.

Wittgenstein asks what would lead someone to view the actions of the thief as if they are inevitable. Who would be inclined to compare the stealing of a banana with the falling of a stone? On the one hand, Wittgenstein points to scientists who may be overly impressed by the regularity of the physical events surrounding the two cases. Fascinated by the extent to which the human body is like a machine, scientists may be tempted to view human behavior as if it were as inevitable and predictable as the falling of a stone. On the other hand, Wittgenstein claims that lawyers may also be tempted to view the actions of the thief in the same fatalistic manner. Defense attorneys, for instance, will want to absolve the thief from legal and moral responsibility. And even though they would admit that the thief was physically responsible for the theft, they will argue that insofar as his actions were necessary (that is, he could not have done otherwise), the thief is not morally culpable and should not be retributively punished.

In response to these considerations, Wittgenstein once again reminds us that despite the popularity and success of the hard determinist's point of view, we can view the thief's actions 
through the lens of indeterminism just as sensibly as we can view them through the lens of determinism (LFW 1993: 432). Indeed, even if we are eventually able to fully predict human behavior, how can we say for certain from our current limited vantage point how we will react to such a profound development in the future? Perhaps the hard determinist is correct that we will want to absolve humans of moral responsibility entirely. But perhaps we will still want to hold people responsible despite the fact that we are able to fully predict their behavior. And because there is nothing about predictability or regularity that logically precludes our still holding people responsible for their actions, Wittgenstein suggests that the best we can presently do is speculate about how we might respond. Thus, by his lights, it is just as reasonable to expect that we will continue to hold people responsible as it is to expect that we won't.

In an attempt to show the intuitive plausibility of both responses, Wittgenstein introduces the following thought experiment: "Imagine we had a smooth plane with a motor car on it. We put no-one inside. Steering wheel and throttle might be fixed, so it might go in a straight line. We could imagine that the steering wheel and throttle were wobbly so the motor described a queer path" (LFW 1993: 433). It is clear that in some sense, the direction of the car is entirely determined by the movements of the steering wheel. Accordingly, we could quite reasonably say that the movement of the vehicle is entirely unfree. But, we could just as easily say that the wheel itself moves without being determined by anything. In this case, we would say that the movement of the car is not determined at all, that the car is free, etc. Thus, by Wittgenstein's lights, we can assume there must be some law which determines the path of the vehicle-even if we have no idea what law is doing the determining-just as sensibly as we can assume that 
there is no law at all. As he says, "are we compelled to say that the steering wheel is free? No. You might go on looking for some law. On the other hand, you might give up entirely and say the steering wheel is free. You might choose to look at it this way or you might not do so" (LFW 1993: 433). Applying this example to the case of the stolen banana, Wittgenstein claims:

It seems as if, if you are very strongly impressed by the responsibility which a human being had for his actions, you are inclined to say that these actions and choices cannot follow natural laws. Conversely, if you are very strongly inclined to say that they do follow natural laws, then you are inclined to say I can't be made responsible for my choice. That you are inclined in this way, I should say, is a fact of psychology. (LFW 1993: 433)

On my reading, this quotation represents the most crucial insight of the entire LFW 1993, namely, that whether or not you are inclined to view the thief's actions as free or unfree depends heavily on your psychological constitution. By Wittgenstein's lights, the difference between the hard determinist and the indeterminist is driven by conflicting underlying attitudes, dispositions, and intuitions. This emphasis on the psychological underpinnings of the free will debate connects up with his following remarks about the importance of temperament from Culture and Value: "It is sometimes said that a man's philosophy is a matter of temperament, and there is something in this. A preference for certain similes could be called a matter of temperament and it underlies far more disagreements than you might think" (VB 1980: 20e).

I would like to take a moment to compare Wittgenstein's remarks about the role differences in temperament play in shaping our philosophical beliefs about the freedom of the will with the following remarks by William James:

And the truth is that facts practically have hardly anything to do with making us either determinist or indeterminists. Sure enough, we make a flourish of quoting facts this way or that; and if we are determinists, we talk about the infallibility with which we can predict 
one another's conduct; while if we are indeterminists, we lay great stress on the fact that it is just because we cannot foretell one another's conduct [...] that life is so intensely anxious and hazardous a game [...] What divides us into possibility men and antipossibility men is different faiths or postulates-postulates of rationality. To this man the world seems more rational with possibilities in it-to that man more rational with possibilities excluded. (1897: 119)

James suggests that because the hard determinist and indeterminist have different "postulates of rationality" they will invariably describe and interpret the same underlying facts differently. In Pragmatism and the Meaning of Truth, James fleshes this notion out in the following way: "The history of philosophy is to a great extent that of a certain clash of human temperaments [...] Yet, his temperament really gives him a stronger bias than any of his more strictly objective premises. It loads the evidence for him one way or the other" (James 1907: 11). By James' lights, it is often helpful to divide philosophers into two camps based on their respective psychological constitutions, namely, the "tender-minded" or "sentimental" - who are often "rationalistic, intellectualistic, idealistic, optimistic, religious, free-willist, monistic, and dogmatical"-and the "tough-minded" or "hard-hearted" - who are often "empiricist, sensationalistic, materialistic, pessimistic, irreligious, fatalistic, pluralistic, and sceptical" (James 1907: 11). ${ }^{4}$

According to both James and Wittgenstein, the disagreement between the hard determinist and the indeterminist is not one that can be settled by appealing to the facts because it is the very facts themselves that are in question. Whereas the hard determinist sees only necessary events and causal explanations, the indeterminist sees openness and free actions.

\footnotetext{
${ }^{4}$ Whether this is right way of carving out the psychological domain is an issue for another day. For now, the key point is that psychological different often underlie metaphysical disagreements without out realizing that this is the case.
} 
Thus, there is a clear affinity between the way Wittgenstein and James treat the free will debate given that both philosophers explicitly suggest that the disagreement between hard determinists and indeterminists is really a debate fueled by differences in the way people with different psychological dispositions view the world and their place in it. ${ }^{5}$ In this sense, it doesn't make sense to talk about the right or wrong view about freedom of the will any more than it makes sense to talk about someone having the right or wrong personality. On this view, the debate can't be solved by appealing to the metaphysical structure of the world-rather, it can merely be elucidated by appealing to the psychological properties of the participants themselves (some of whom are intuitively drawn to determinism, some of whom are intuitively drawn to indeterminism). I take this to be the key insight of Wittgenstein's Lectures on Freedom of the Will.

If Wittgenstein is right on this front, philosophical theories about free will are akin to posthoc rationalizations of one's underlying attitudes and intuitions-which are in turn shaped by one's psychological dispositions. Rather than impartial reason driving one's metaphysical views, these views are the result of motivated cognition. For example, there is a growing literature on political psychology which suggests that while the commitment to ideological conservativism appears to be impartial and theory-driven, it is largely the result of underlying psychological factors such as personality (e.g., authoritarianism, dogmatism, and intolerance of ambiguity), epistemic and existential needs (e.g., the need for closure and terror management), and ideological rationalization (e.g., social dominance). ${ }^{6}$ So, while conservatives have constructed

\footnotetext{
${ }^{5}$ There is empirical evidence for Wittgenstein's thesis that personality type influences people's beliefs about free will. See, e.g., Feltz and Cokely (2009).

${ }^{6}$ See, e.g., Jost, Glaser, Kruglanski, and Sulloway (2003).
} 
elaborate theories to support the political ideology that they take to be compelling and objectively true, their commitment to conservativism is grounded in and driven by their underlying psychological dispositions. This empirical research on political psychology ties directly into some recent studies which suggest that free will beliefs are similarly correlated with a number of these same psychological factors (e.g., authoritarianism, just world beliefs, and tolerance for inequality). ${ }^{7}$ These and related findings suggest that the belief in free will is also likely driven by motivated cognition. In both cases, the psychological tail appears to be wagging the metaphysical dog. In this respect, I think that Wittgenstein's claim that our beliefs in determinism and indeterminism are influenced to a large extent by our temperament is supported by recent work in social psychology. In this way, the gathering empirical research on motivated cognition breathes new life into Wittgenstein's remarks in his first lecture on freedom of the will concerning the role played in philosophical debates by psychological dispositions.

As for the second lecture, Wittgenstein begins by having us imagine a piece of paper that makes decisions where it is to go, but nevertheless is blown one way or another by the wind. Now suppose that the wind not only blows the piece of paper about, "but in a different way moves its decisions" (LFW 1993: 434). One way to respond to the condition of the piece of paper is to say that despite its decisions, the piece of paper is unfree. This reaction, by Wittgenstein's lights, represents only one possible way of looking at the facts. We might even be tempted to view our own actions and decisions in the same way that we view the piece of paper's decisions

\footnotetext{
${ }^{7}$ See, e.g., Nadelhoffer and Goya-Tocchetto (2013).
} 
and movements. In this case, we might be inclined to say, "we are all the time being determined. We think we decide, but all the time we are being shoved about, our decisions" (LFW 1993: 434). Wittgenstein's response is that, "normally, unless we philosophize, we don't talk this way. We talk of making decisions. Is there a case in which we would actually say that a man thought he decided, but actually didn't decide?" (LFW 1993: 434).

In answering this question, Wittgenstein introduces yet another example. He first contrasts being in prison-where you are not free to do what you want-with being in a room where you are free to go wherever you want. But suppose that in the room below, there is someone controlling all of your movements with some sort of mechanistic device such that you go where the operator wants you to go. If you are oblivious to the operator and his machine and you were asked whether you are moving about freely, you would obviously insist that you are free even though you are not. And while this example is admittedly fanciful, there are real life cases that are strikingly similar. Wittgenstein mentions the case of a magician who can make people "choose the card he wanted them to choose" even though they believe they are choosing the card freely. Here we have a real case where someone thinks they are freely making a decision when in fact their decision is actually being controlled or manipulated. So, Wittgenstein concludes that it is possible to "describe a case in which you would definitely say: He thinks he is free, but we are really regulating all of his movements" (LFW 1993: 434).

But despite the fact that such a case is possible, Wittgenstein finds it puzzling that we are tempted to compare those special cases where we would say that someone "was deciding freely, but was actually compelled" with everyday situations (LFW 1993: 435). After all, the abnormal 
cases are only identifiable as such if there is a legitimate contrast between normal cases-where I act on my own decisions and hence act freely and responsibly-and special cases-where I act as I do as the result of some type of internal or external compulsion. Wittgenstein explains the hard determinist's willingness to treat the special case as if it were a normal case with the following remark: "Given a certain attitude, you may be, for reasons unknown, compelled to look at it in a certain way. A certain image can force itself upon you" (LFW 1993: 435).

Suppose, for instance, that you have lost your keys and that you are frantically looking for them. In this type of situation, you may be overwhelmed by the feeling that you are not free (or that you are compelled). This is to say, given certain conditions, we may be inevitably led to adopt a fatalistic attitude towards our own decisions and actions. But Wittgenstein asks, "must you look at looking for something in this way? No. But it is one of the most important facts of human life that such impressions sometimes force themselves on you" (LFW 1993: 435). By his lights, it is a fact of human psychology that we sometimes feel as if what happens is the result of forces entirely beyond our control just as we sometimes feel that what happens is entirely up to us. In this respect neither viewing people as free nor viewing them as unfree is intellectually necessary even if sometimes viewing them in these competing ways may be psychologically unavoidable.

At this point, Wittgenstein focuses instead on the hard determinist's claim that, "if we really assume that his actions follow natural laws, let us assume that we knew these laws; knew the whole working of his cells acting on one another and were therefore able to calculate what he was going to do. This should determine us into saying 'Now we see after all that he isn't 
responsible for his actions" (LFW 1993: 436). Wittgenstein's response to this intuition is that even if it were possible that:

[W] could perform this calculation (of what he was going to do), I don't see why we shouldn't still hold him responsible [...] Suppose I know all and more than physicists and biologists know-why should I say this makes him more analogous to a machineryexcept in so far as I mean that I can forecast better. I don't know why I won't be led to an indeterminist view. (LFW 1993: 436)

This remark is presumably intended to once again remind us that we cannot know now how we would respond if we had the ability to accurately predict behavior, precisely because we currently lack such an ability. As we saw earlier, perhaps we would be led to adopt a fatalistic or deterministic attitude towards the facts but perhaps we would not. One can bring both determinism and indeterminism to bear on almost any facts.

But can't we prove whether the will is free or not? After all, according to some indeterminists, we can learn that we are free by relying on some kind of introspection. In response to the claim that introspection proves that we are free, Wittgenstein asks, "how does one look into oneself and experience free will in oneself?" (LFW 1993: 436). After all, introspection may lead two different individuals to two different conclusions about freedom of the will. Take, for instance, a situation where you have a strong intuition that you are acting freely. Perhaps you are preparing to do something important-e.g., making a difficult moral decision-and you say to yourself that you are not forced to do it and that if you perform the action, it will be because you freely chose to do so. Wittgenstein's point seems to be that these thoughts and feelings do not reveal whether you are really free to chose. This is because someone else in the very same circumstances could have the feeling that they are entirely unfree- 
especially if the person has a desire not to be held responsible or a desire to emphasize the tragic nature of being a human who is forced to do something difficult or important.

Here, Wittgenstein suggests that in order to understand the meaning of "I am free" or "I am unfree" we would have to describe the "thoughts preceding the utterance, and the circumstances under which it is said" (LFW 1993: 439-440). The problem is that two individuals who face the very same circumstances may have very different thoughts and feelings. Whereas the person who feels free may be expressing a desire to assign and assume responsibility, the person who does not feel free may be adopting the aforementioned tragic attitude. When someone adopts the former attitude, they may be inclined to say "no one else is to blame but me," whereas when someone adopts the latter attitude, they may be inclined to say "everything is fated and determined". There is no right or wrong here, metaphysically speaking, there are only conflicting attitudes.

On Wittgenstein's view, these different thoughts and feelings are not about the facts and they are not intended to express scientific laws, that is, they are not about something that could be proven true or false one day (VB 1980: 63). They reflect attitudes that people bring to bear on what happens. The point of saying that one is free or unfree is not to make an empirical statement (far less a metaphysical statement), that is, it is not an attempt to say something informative about some fact of the matter. Presumably, this is because when we make these types of claims, we are not opening ourselves up to refutation if the facts turn out differently-a necessary condition of empirical statements. If I am a die-hard determinist, I can explain away any apparent contingency. If, on the other hand, I am a die-hard indeterminist, I can explain away any apparent 
necessity. Whether I take myself to be free or unfree will depend on my point of view (which is in turn shaped by my temperament), not on the way that the world really is, metaphysically speaking (whatever that is supposed to mean).

Of course, Wittgenstein admits that to say that these types of statements are not "corrected by experience," is "not to say that scientific discoveries have no influence on statements of this sort" (LFW 1993: 440). His suggestion is simply that neither the feelings associated with hard determinism nor the feelings associated with indeterminism are capable of disproof in the same way that empirical beliefs are-that is, they are not falsifiable. The disagreement between the two views is best understood as a disagreement in attitudes and not as a disagreement about the facts. On Wittgenstein's view, "I am free" expresses the attitude of wanting to assign and assume responsibility and "I am not free" expresses a different attitudeperhaps towards the very same underlying facts. But, even though "I am free" and "I am not free" are expressions of different-and seemingly incommensurable-attitudes towards the facts, it is nevertheless possible that discoveries in science could affect these attitudes about the freedom of the will, but only by "redirecting our attention in a particular way" (LFW 1993: 441). Wittgenstein is here simply pointing out that these discoveries do not entail the deterministic attitude, even if they may very well lead more people to adopt such an attitude.

Next, Wittgenstein considers what might happen if scientists discovered all of the laws that governed the human process of deliberation and choice and were able to fully predict what someone is going to choose. The mere possibility of such a discovery leads hard determinists to say, "our apprehension of free will is only due to our ignorance of the laws of nature. If we knew 
these laws, we should know we have no free will" (LFW 1993: 441). Wittgenstein's response is that perhaps, "the knowledge of these laws would simply change the business. There is truth in that. One might say: being able to calculate things we can't calculate now would indeed change the whole situation." (LFW 1993: 441) But it is unclear that we would inevitably stop feeling free and holding people responsible. Here Wittgenstein draws an analogy between how the discovery of such laws would affect our attributions of freedom and responsibility with how they would affect our playing games such as chess and roulette:

If Moore and I play chess or roulette and someone else could predict what was going to happen (telling us), we would just give up playing roulette. Suppose someone said: 'This is no game of chance at all. What makes us think it is a game of chance is only our ignorance'. I could contradict this and say: 'No. It is a game of chance now that we are ignorant; if in the future we were no longer ignorant it would no longer be a game of chance'. We can't even say that if prediction was possible Moore and I would not play the game. You might say: The point of the game would then be different. And the point of choosing would be changed if we had a prediction of it. I would say: you can call it a different game or not call it a different game. (LFW 1993: 443)

On this very cryptic note, Wittgenstein's Lectures on Freedom of the Will draw to a close. Presumably, the moral of the story is that even if we were to discover the laws that explain the roulette board such that we could accurately predict where the ball would land, it doesn't follow that we would no longer play the game-although we would quit betting on it if we could make these predictions in real time. But if we couldn't make the predictions in real time, it is feasible that we would keep betting on the game even though it would be theoretically possible to predict the outcome. And I take Wittgenstein's point to be that the same can be said of the possibility of our one day being able to predict all of human behavior. Maybe the hard determinist is correct in assuming that we will no longer hold people morally responsible. But perhaps we will simply 
keep on blaming people despite the truth of determinism. After all, eradicating attitudes and feelings-which cannot be shown to be true or false-is often much more difficult than abandoning false beliefs. And even though Wittgenstein does not believe that our various attitudes about the freedom of the will can be true or false, he has at least managed to reveal some of the shortcomings of the beliefs that motivate these genuinely conflicting attitudes (e.g., that laws are like rails or that we can prove that we are free via introspection).

\section{Placing Wittgenstein in the Free Will Debate}

As is often the case with Wittgenstein, it is hard to decide exactly where he fits into the traditional philosophical debate about freedom of the will-if he fits into it at all. On the one hand, Wittgenstein is attempting to undermine the force of the debate between hard determinists and indeterminists by focusing on the deeply entrenched and conflicting attitudes and desires that underlie the debate, rather than treating it as if it were fueled purely by empirical or metaphysical concerns. On the other hand, Wittgenstein explicitly avoids arguing that we are either free or unfree. Thus, on my reading, it would be a mistake to assume that Wittgenstein is simply offering an inchoate version of compatibilism - that is, the philosophical theory that we can be both free and causally determined by natural laws. I believe this is a mistake for two reasons: First, the two attitudes that Wittgenstein says underlie our beliefs about the freedom or unfreedom of the will are incommensurable. On his view, while we can and often do switch back and forth between these two conflicting points of view, we cannot adopt both views simultaneously. Second, to the extent that compatibilism is a philosophical theory that commits one both to the existence of free will and to the compatibility between free will and determinism, we have good reason to 
suspect that Wittgenstein would withhold his endorsement. After all, according to his atheoretical conception of philosophy, philosophers should avoid putting forth theses and they should not attempt to develop metaphysical theories. Instead, philosophers-unlike scientistsshould limit themselves to a purely descriptive methodology. As he says:

We may not advance any kind of theory. There must not be anything hypothetical in our considerations. We must do away with all explanation, and description alone must take its place. And this description gets its light, that is to say its purpose, from the philosophical problems. These are, of course, not empirical problems; they are solved, rather, by looking at the workings of our language. The problems are solved, not by giving new information, but by rearranging what we have always known. (PI 1958: 109)

As such, I think it would be wrongheaded to attribute a particular theory of free will to Wittgenstein. What he was offering instead was a diagnosis of the debate between the competing camps of the free will debate by focusing on competing ways we might think and talk about free and unfree action. In doing so, he hoped that this might dissolve the intractable nature of the debate by reminding us that there is no metaphysical puzzle about freedom of the will that must (yet somehow cannot) be solved. Instead, once we see the pseudo-problem of free will aright - that is, as the result of competing language games fueled by disparate psychological predispositions - the problem is dissolved, "like a lump of sugar in water." (PH 1993: 183) We are neither categorically free nor categorically unfree and determinism is neither categorically true nor false. Whether we're free or unfree and whether determinism is true or false, will depend both on the context and on our particular point of view-which is rooted in psychology and not metaphysics. So, while it is commonplace to simply ignore Wittgenstein's insistence that he is 
not offering philosophical theories, I believe interpreting him in this way often does an injustice to the spirit of his philosophical investigations.

On my reading of the Lectures on Freedom of the Will, Wittgenstein is not attempting to offer a novel account about the nature and limits of free will, but rather he is attempting to diagnose and describe the deeply entrenched attitudes, beliefs, desires, and dispositions that lead to the formation of the two irreconcilable factions of the free will debate (that is, incompatibilism and compatibilism). And by reminding us of the primary role played by temperaments and attitudes in shaping the differences in opinion about whether and when humans are free and responsible, Wittgenstein tries to reorient the debate in a way that properly reflects the true nature of the disagreement between the two camps. This fits well with the history of the free will debate where there has been little progress since the time of the ancients. Is it possible that differences in temperament and disagreements in attitude have played a much bigger role in fueling the free will debate than most philosophers have been willing to admit? Wittgenstein clearly thought so. And I find myself agreeing with him. If nothing else, I hope that my analysis of Wittgenstein's lectures gives philosophers who are party to the free will debate sufficient reason to give these lectures a second look. Of course, many scholars will resist Wittgenstein's diagnosis of the psychological (as opposed to metaphysical) origins of the free will debate. After all, rather than attempting to develop a metaphysical theory of free will, he tries to dissolve the problem by showing that the desire for such a theory is as confused and misguided as it is unnecessary. 


\section{Acknowledgment}

I would like to take this opportunity to thank Professor Robert Arrington for all that he taught me about Wittgenstein during our time together. He had a lot more to teach than I had the capacity to learn. Nevertheless, we carefully went through Wittgenstein's Lectures on Freedom of the Will together during the summer of 2000 and this rewarding experience inspired me to write the present paper. That I didn't manage to write anything until now-nearly two decades later-is testimony to how perplexing some of the passages can be. I would like to think that if Professor Arrington were still with us, he would be pleased with how it turned out. Without his help and inspiration, this paper never would have been possible.

\section{References}

Brenner, William, H. 2001. "Natural Law, Motives, and Freedom of the Will". Philosophical Investigations 24(3), 246-61.

Dilman, Ilham. 1999. Free Will: An Historical and Philosophical Introduction. London: Routledge.

Feltz, Adam., and Edward Cokely. 2009. "Do Judgments about Freedom and Responsibility Depend on Who You Are? Personality Differences in Intuitions about Compatibilism and Incompatibilism". Consciousness and Cognition 18(1), 342-250.

James, William. 1975. Pragmatism and The Meaning of Truth. Cambridge, MA: Harvard University Press. Originally published in 1907.

James, William. 1979. "The Dilemma of Determinism". In: The Will to Believe and Other Essays in Popular Philosophy. Cambridge, MA: Harvard University Press. Originally published in 1897.

Jost, John. T., Jack Glaser, Arie Kruglanski, and Frank J. Sulloway. 2003. "Political Conservatism as Motivated Social Cognition". Psychological Bulletin 129(3), 339-375.

Nadelhoffer, Thomas, and Daniela Goya-Tocchetto. 2013. "The Potential Dark Side of Free Will: Some Preliminary Findings. In Gregg Caruso, ed., Exploring the Illusion of Free Will and Moral Responsibility. Lanham, MD: Lexington Books, 121-140.

Shanker, Stuart. 1993. "Wittgenstein versus James and Russell on the Nature of Willing." In: J.V. Canfield and S.G. Shanker, eds., Wittgenstein's Intentions. New York: Routledge, 195-239.

Wittgenstein, Ludwig. 1955. Tractatus Logico-Philosophicus. Hg. von C. K. Ogden, übersetzt von C. K.Ogden und F. P. Ramsey. International Library of Psychology, Philosophy and Scientific 
Method. London: Routledge and Kegan Paul. [Mit einem Register von Max Black. Einleitung auf Englisch von Bertrand Russell. Deutsch mit englischer Übersetzung] (TLP 1955 1955)

Wittgenstein, Ludwig. 1958. Philosophical Investigations / Philosophische Untersuchungen. Hg. Von G. E. M. Anscombe und R. Rhees, übersetzt von G. E. M. Anscombe. Second edition. Oxford: Basil Blackwell. [Deutsch mit englischer Übersetzung] (PI 1958)

Wittgenstein, Ludwig. 1967. Zettel / Zettel. Hg. von G. E. M. Anscombe und G. H. von Wright, übersetzt von G. E. M. Anscombe. Oxford: Basil Blackwell. [Deutsch mit englischer Übersetzung] (Z 1967)

Wittgenstein, Ludwig. 1978. Remarks on the Foundations of Mathematics. Hg. von G. H. von Wright, R. Rhees und G. E. M. Anscombe, übersetzt von G. E. M. Anscombe. Third edition, revised and reset. Oxford: Basil Blackwell. [Mit einem ausführlichen Inhaltsverzeichnis und einem Register. Englische Übersetzung] (RFM 1978)

Wittgenstein, Ludwig. 1979. “Notebooks 1914-1916". In: Notebooks 1914-1916, S. 2-91. Hg. Von G. H. von Wright und G. E. M. Anscombe, übersetzt von G. E. M. Anscombe. Second edition. Oxford: Basil Blackwell. [Mit einem Register von E. D. Klemke und Ali Enayat. Deutsch mit englischer Übersetzung] (TB 1979)

Wittgenstein, Ludwig. 1980. Culture and Value / Vermischte Bemerkungen. Hg. von G. H. von Wright unter Mitarbeit von Heikki Nyman, übersetzt von Peter Winch. Amended second edition. Oxford: Basil Blackwell. [Mit Registern. Deutsch mit englischer Übersetzung] (VB 1980)

Wittgenstein, Ludwig. 1992. Last Writings on the Philosophy of Psychology / Letzte Schriften über die Philosophie der Psychologie. Bd. 2. Hg. von G. H. von Wright und Heikki Nyman, übersetzt von C. G. Luckhardt und Maximilian A. E. Aue. Oxford:Basil Blackwell. [Mit einem Register der Übersetzer. Deutsch mit englischer Übersetzung] (LW 1993)

Wittgenstein, Ludwig. 1993. „Philosophie“ In: Philosophical Occasions 1912-1951, S. 158-199. Hg. und eingeleitet von James C. Klagge und Alfred Nordmann. Indianapolis and Cambridge, USA: Hackett. [Deutsch mit englischer Übersetzung] (PH 1993)

Wittgenstein, Ludwig. 1993. "Lectures on Freedom of the Will." In Philosophical Occasions 19121951, S. 427-444. Hg. und eingeleitet von James C. Klagge und Alfred Nordmann. Indianapolis and Cambridge, USA: Hackett. [Englisch.] (LFW 1993 1993) 